\title{
ADVANCES IN SHOCK COMPRESSION OF MANTLE MINERALS AND IMPLICATIONS
}

\author{
Thomas J. Ahrens, Paul D. Asimow and Jed L. Mosenfelder \\ Division of Geological and Planetary Sciences, \\ California Institute of Technology, Pasadena, CA 91125 USA
}

\begin{abstract}
Hugoniots of lower mantle mineral compositions are sensitive to the conditions where they cross phase boundaries including both polymorphic phase transitions and partial to complete melting. For $\mathrm{SiO}_{2}$, the Hugoniot of fused silica passes from stishovite to partial melt $(73 \mathrm{GPa}$, $4600 \mathrm{~K}$ ) whereas the Hugoniot of crystal quartz passes from $\mathrm{CaCl}_{2}$ structure to partial melt (116 $\mathrm{GPa}, 4900 \mathrm{~K}$ ). For $\mathrm{Mg}_{2} \mathrm{SiO}_{4}$, the forsterite Hugoniot passes from the periclase $+\mathrm{MgSiO}_{3}$ (perovskite) assemblage to melt before $152 \mathrm{GPa}$ and $4300 \mathrm{~K}$, whereas the wadsleyite Hugoniot transforms first to periclase $+\mathrm{MgSiO}_{3}$ (post-perovskite) and then melts at $151 \mathrm{GPa}$ and $4160 \mathrm{~K}$. Shock states achieved from crystal enstatite are molten above $160 \mathrm{GPa}$. High-pressure Grüneisen parameters for molten states of $\mathrm{MgSiO}_{3}$ and $\mathrm{Mg}_{2} \mathrm{SiO}_{4}$ increase markedly with compression, going from 0.5 to 1.6 over the 0 to $135 \mathrm{GPa}$ range. This gives rise to a very large $(>2000 \mathrm{~K})$ isentropic rise in temperature with depth in thermal models of a primordial deep magma ocean within the Earth. These magma ocean isentropes lead to models that have crystallization initiating at midlower mantle depths. Such models are consistent with the suggestion that the present ultra-low velocity zones, at the base of the lowermost mantle, represent a dynamically stable, partially molten remnant of the primordial magma ocean. The new shock melting data for silicates support a model of the primordial magma ocean that is concordant with the Berkeley-Caltech iron core model [1] for the temperature at the center of the Earth.
\end{abstract}

Keywords: Silicate liquids, Grüneisen parameter, geotherm, magma ocean, early Earth PACS: $62.50 . \mathrm{Ef}, 91.35 . \mathrm{Lj}, 91.45 . \mathrm{Nc}, 91.60 . \mathrm{Hg}$

\section{INTRODUCTION}

Earlier shock wave research focused on comparing densities achieved at high pressure $(P)$ to seismologically derived density versus depth profiles for the deep Earth to infer its chemical composition [2, 3]. Later equation of state research focused on measuring Grüneisen's ratio at high $P$ from Hugoniot measurements on compositions with different initial densities [4], and by measuring high-pressure sound velocities [5]. Shock temperature measurements on mantle minerals were motivated by the need for additional constraints on Grüneisen's ratio, specific heats and the thermodynamics of phase changes, including melting [6]. Two unanticipated discoveries reinvigorated this research area:

1. Akins and Ahrens [7] demonstrated that the previous shock data for $\mathrm{SiO}_{2}$ polymorphs were not "scattered" but represented transformation to post-stishovite phases $\left(\mathrm{CaCl}_{2}\right.$ and $\alpha-\mathrm{PbO}_{2}$ structures) with increasing $P$. Moreover, within the shock-induced melting 
regime, transformation of the melt from 6-fold to 8 -fold or higher coordination appeared to occur.

2. Superheating of shock-induced highpressure phases and then, over a very small $P$ range, achievement of states representing substantial melt, result in spectacular decreases in Hugoniot temperatures. This was first seen for melting of stishovite and $\mathrm{SiO}_{2}\left(\mathrm{CaCl}_{2}\right.$-structure) produced from fused and crystal $\mathrm{SiO}_{2}$, respectively. Further research indicates such super-heating behavior precedes shock melting for the high-pressure phases of $\mathrm{Mg}_{2} \mathrm{SiO}_{4}$ and $\mathrm{MgSiO}_{3}$.

We summarize recent Hugoniot results for $\mathrm{Mg}_{2} \mathrm{SiO}_{4}$ forsterite and wadsleyite and for $\mathrm{MgSiO}_{3}$ glass and crystal (enstatite), which all demonstrate transformation to lower mantle minerals and then melting. Some implications of these results with respect to recent theories describing the primordial molten Earth are given.

\section{TRANSFORMATION AND MELTING}

Previous Hugoniot data for $\mathrm{SiO}_{2}$ over a range of initial polymorphs (both solid and porous) demonstrate transformation to stishovite and $\mathrm{CaCl}_{2}$ structure followed by melting (Fig. 1).

Hugoniot temperatures (Fig. 2) for $\mathrm{SiO}_{2}$ glass and crystal quartz appear to be insensitive to the time scales of shock duration. Decaying laser shock data of Hicks et al. [8] and steady gas-gun data of Lyzenga et al. [6] both show super-heating prior to melting behavior despite shock durations of $\sim 10^{-9}$ and $10^{-6} \mathrm{~s}$, respectively.

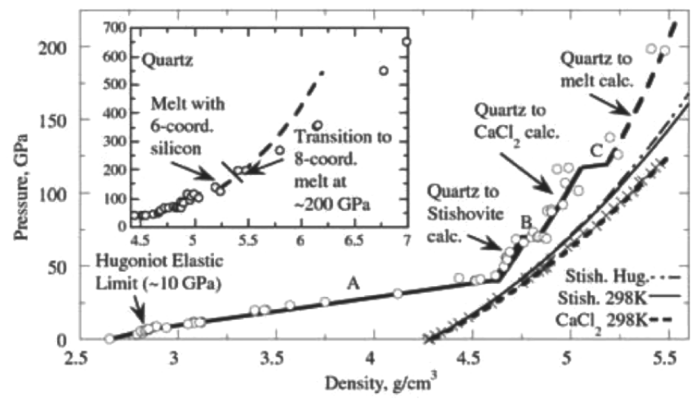

Figure 1. New interpretation of Hugoniot of crystal $\mathrm{SiO}_{2}$. Circles are previous shock wave data; crosses are static compression data. A, B and $\mathrm{C}$ indicate regimes of transformation between phases (modified from [7]).
Although the [8] and [6] data are remarkably concordant, the peak for super-heated stishovite (from fused $\mathrm{SiO}_{2}$ ) around $70 \mathrm{GPa}$ in the [8] data occurs some $2-5 \mathrm{GPa}$ higher than in [6]. Both data sets for quartz indicate the peak for superheated $\mathrm{CaCl}_{2}$ structure occurs at $\sim 110 \mathrm{GPa}$. Melt beyond the superheating peak of crystal quartz may coexist with the $\alpha-\mathrm{PbO}_{2}$ structure.

The $\mathrm{SiO}_{2}$ shock temperatures inferred for melting at 70 and $110 \mathrm{GPa}$ yield a melting line slope of $\sim 11 \mathrm{~K} / \mathrm{GPa}$ and a melt that is less dense than the solid by $\sim 3 \%$ according to Lyzenga et al [6]. However, we note that because of the now recognized minor changes in structure between stishovite, $\mathrm{CaCl}_{2}$ - and $\alpha-\mathrm{PbO}_{2}$-structured phases, this argument may be somewhat vulnerable.

The Hugoniots of $\mathrm{Mg}_{2} \mathrm{SiO}_{4}$ (forsterite, wadsleyite) and $\mathrm{MgSiO}_{3}$ (glass, enstatite and perovskite structure) all show transformation to high-pressure phases and, with the exception of $\mathrm{MgSiO}_{3}$ initially in the perovskite structure, display the onset of melting (Figs. 3 and 4). Shock temperatures, measured or modeled from $U_{\mathrm{s}}-U_{\mathrm{p}}$ data, for $\mathrm{MgSiO}_{3}$ crystal and glass are shown in Fig. 4. As for various polymorphs and porosities of $\mathrm{SiO}_{2}$ and $\mathrm{Mg}_{2} \mathrm{SiO}_{4}$, superheated solid states are observed before melting.

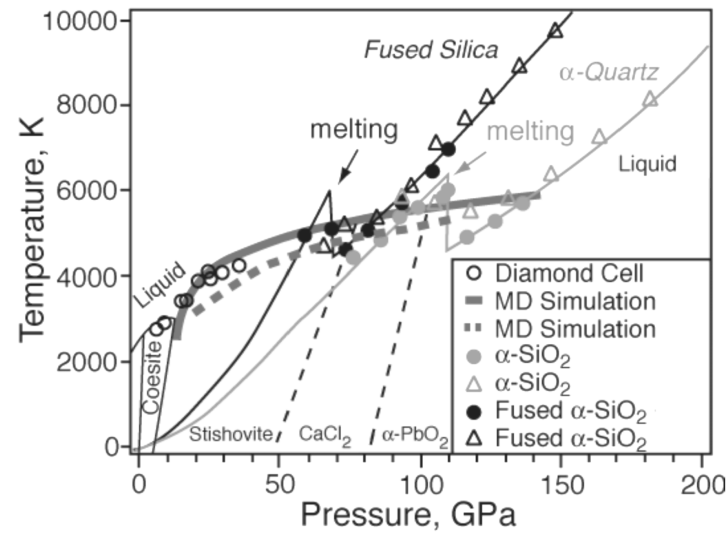

Figure 2. Shock temperatures for decaying (duration $10^{-9} \mathrm{~s}$ ) laser-driven shocks in crystal and fused silica (dark and light hollow triangles) from [8]. Also shown: melting of coesite and stishovite in diamond cell and two molecular dynamics calculations of stishovite melting. Filled light and dark circles are shock temperatures of initially crystal quartz and fused silica [6], respectively, for steady shocks (durations, $\sim 10^{-6} \mathrm{~s}$ ), adapted from R.S.McWilliams (Pers. Comm.., 2007). 


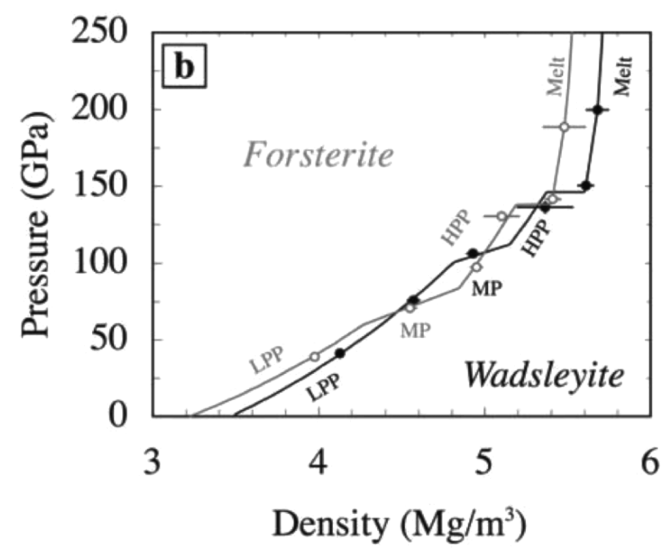

Figure 3. Hugoniots for $\mathrm{Mg}_{2} \mathrm{SiO}_{4}$ forsterite (Fo) and wadsleyite (Wd) initial states. LPP indicates initial low pressure Fo or Wd phase. MP means mixed, lowpressure and high-pressure phase. HPP means highpressure phase, which for Fo is $\mathrm{MgSiO}_{3}$ perovskite + $\mathrm{MgO}$, whereas for Wd HPP means $\mathrm{MgSiO}_{3}$ postperovskite $+\mathrm{MgO}$. Melt is molten $\mathrm{Mg}_{2} \mathrm{SiO}_{4}$. From [9] .

The Hugoniot data for $\mathrm{MgSiO}_{3}$ enstatite, like the data for $\mathrm{Mg}_{2} \mathrm{SiO}_{4}$ of Fig. 3, indicates the onset of melting by a several percent density increase along the Hugoniot, in this case at $\sim 170$ GPa. An increase in density upon equilibrium melting requires a negative melting curve slope. However, one cannot immediately conclude from these data that the melt phase must be denser than the coexisting solid! The shocked solid is super-heated just before melting such that just above the onset of melting, the state of the melt is $\sim 10^{2}$ to $\sim 10^{3} \mathrm{~K}$ cooler. At high $P$, if melt and solid densities are within a few percent, then thermal contraction can increase the melt density enough to appear (along the Hugoniot) denser than the solid. Present knowledge of thermal expansions at high $P$ and temperature for both phases are insufficient to forge conclusions about intrinsic melt-solid density contrast using just thermal equations of state.

The equation of state data used to construct theoretical shock temperature models of Fig. 4 are summarized in Table 1. Shock temperatures were not measured for initially $\mathrm{MgSiO}_{3}$ glass shocked into the super-heated perovskite regime. The data for initially enstatite are assigned to the superheated post-perovskite regime and appear discrepant with the much hotter (probably

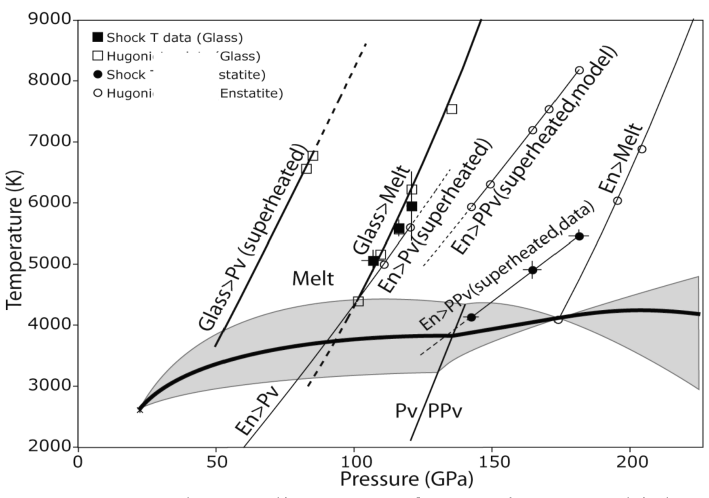

Figure 4. Phase diagram of $\mathrm{MgSiO}_{3}$ at high temperatures and $P$ using measured $[10,11]$ and calculated (based on EOS of [12]) Hugoniot temperatures for $\mathrm{MgSiO}_{3}$ glass and enstatite, and, the majorite-perovskite-melt triple point $(22.5 \mathrm{GPa}, 2600$ $\mathrm{K})$.

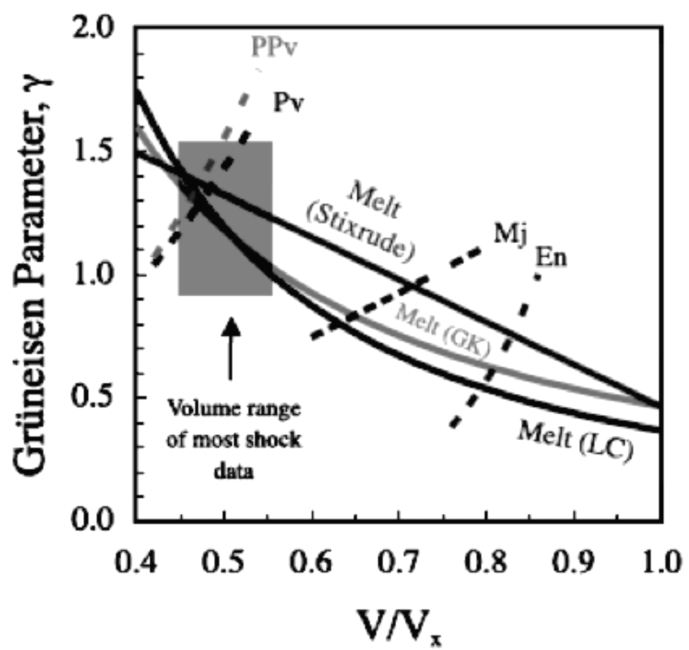

Figure 5. Grüneisen's ratio vs. compression for slightly different ( $\mathrm{LC}$ and $\mathrm{GK}$ ) $\mathrm{MgSiO}_{3}$ melt models and solid phases (dashed), after [12].

incorrect) theoretical models. The data indicate a minimal superheating peak; the models indicate unreasonably large superheated temperatures.

Thus the Fig. 4 data and calculations allow a broad peak in $\mathrm{MgSiO}_{3}$ melting temperatures (at lowermost mantle $P$ ) ranging from 2600,3600 , 4300 , and $4000 \mathrm{~K}$ at $22.5,50,100,170 \mathrm{GPa}$, respectively. Finally we note the strong increase in Grüneisen's ratio of molten $\mathrm{MgSiO}_{3}$ with compression demonstrated in [12] (Fig. 5). 


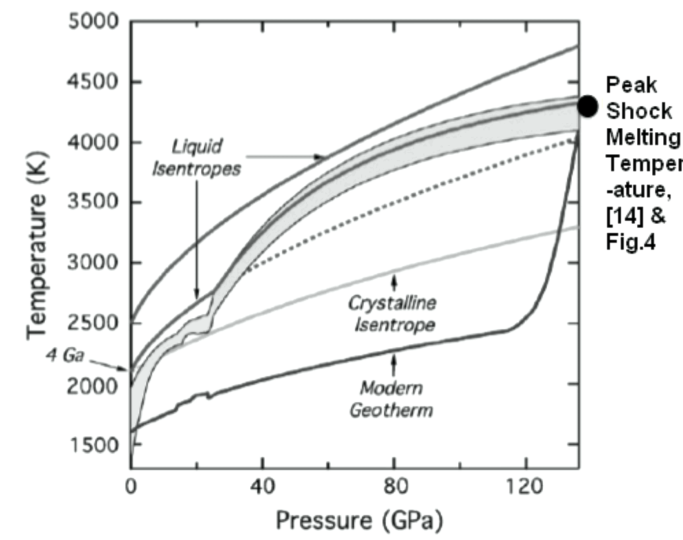

Figure 6 Magma ocean temperatures along liquid isentropes at Earth formation (base, $4800 \mathrm{~K}$ ) and upon partial crystallization (at $4 \mathrm{Ga}$ ) (base, $4300 \mathrm{~K}$, which is peak shock melting temperature). Modified from [13].

\section{IMPLICATIONS FOR EARTH}

The peak temperatures obtained for melting of $\mathrm{MgSiO}_{3}$ here and for $\mathrm{Mg}_{2} \mathrm{SiO}_{4}[14]$ at $133 \mathrm{GPa}$ agree closely with initial crystallization temperatures (at $4 \mathrm{Ga}$ ). These also may represent peak temperatures for base of modern mantle, and, taken with the broad maximum in melt temperature (Fig. 4) may explain why the basal partial melt layer is nearly equal in density to solids, stable, and thus possibly a remnant of the magma ocean. Finally, the high values of

Table 1. Model parameters for Hugoniot temperature calculations in $\mathrm{MgSiO}_{3}$ system [12].

\begin{tabular}{|l|l|l|l|}
\hline & $\mathrm{Pv}$ & $\mathrm{PPv}$ & Melt \\
\hline$V_{\mathrm{o}}\left(\mathrm{cm}^{3} \mathrm{~kg}^{-1}\right)$ & 243.477 & 243.402 & 382.02 \\
\hline$K_{\mathrm{o}}(\mathrm{GPa})$ & 254.7 & 225 & 24.7 \\
\hline$K^{\prime}$ & 4.26 & 4.21 & 9.2 \\
\hline$K^{\prime}\left(\mathrm{GPa}^{-1}\right)$ & & & -1.87 \\
\hline$\gamma_{\mathrm{o}}$ & 2.23 & 2.61 & 0.37 \\
\hline$q$ & 1.83 & 2.1 & -1.71 \\
\hline$C_{\mathrm{vm}}\left(\mathrm{J} \mathrm{K}^{-1} \mathrm{~kg}^{-1}\right)$ & 806 & 1035 & 1691 \\
\hline$\theta_{\mathrm{o}}(\mathrm{K})$ & 736 & 990 & \\
\hline $\mathrm{d} \ln C_{\mathrm{v}} / \mathrm{dln} V$ & & & 1.31 \\
\hline $\mathrm{E}_{\mathrm{tr}}(\mathrm{J} / \mathrm{g}$, from En $)$ & 1100 & 1189 & 2192 \\
\hline
\end{tabular}

$\mathrm{Pv}$ and PPv models are $3^{\text {rd }}$ order Birch-Murnaghan (BM) isentropes with Mie-Grüneisen thermal pressure and Debye heat capacity. Melt is a $4^{\text {th }}$ order BM isentrope with Mie-Grüneisen thermal pressure, and $C \mathrm{v}(V)=C_{\mathrm{vm}} \exp \left\{\left(V / V_{\mathrm{o}}\right)^{\mathrm{dlnCv} / \mathrm{dn} \mathrm{V}}\right\}[12]$.
Grüneisen's ratio (Fig. 5) for magma oceans led to very high temperatures at the core-mantle interface upon Earth accretion (Fig. 6). Upon temperature extrapolation to the Earth's center they are in accord with present estimates. This implies that only the mantle underwent significant cooling during Earth history.

\section{REFERENCES}

1. Q. Williams, R. Jeanloz, J. Bass, B. Svendsen and T. J. Ahrens, Science 236, 181 (1987).

2. D. L. Anderson, Earth And Planetary Science Letters 5 (2), 89 (1968).

3. F. Birch, Journal of Geophysical Research 69, 4377 (1964).

4. R. G. McQueen, J. N. Fritz and S. P. Marsh, Journal of Geophysical Research, 68, 2319 (1963).

5. J. M. Brown, M. D. Furnish and R. G. McQueen, in High-Pressure Research in Mineral Physics, edited by M. H. Manghnani and Y. Syono (American Geophysical Union, Washington, DC, 1987), pp. 373-384.

6. G. A. Lyzenga, T. J. Ahrens and A. C. Mitchell, Journal of Geophysical Research 88, 2431 (1983).

7. J. A. Akins and T. J. Ahrens, Geophysical Research Letters 29, 1394 (2002).

$8 . \quad$ D. G. Hicks, T. R. Boehly, J. H. Eggert, J. E. Miller, P. M. Celliers and G. W. Collins, Physical Review Letters 97, 025502 (2006).

9. J. L. Mosenfelder, P. D. Asimow and T. J. Ahrens, Journal Of Geophysical Research 112, B06208 (2007).

10. J. A. Akins, S. N. Luo, P. D. Asimow and T. J. Ahrens, Geophysical Research Letters 31, L14612 (2004).

11. S. N. Luo, J. A. Akins, T. J. Ahrens and P. D. Asimow, Journal of Geophysical Research 109, B05205 (2004).

12. J. L. Mosenfelder, P. D. Asimow, D. J. Frost, D. C. Rubie and T. J. Ahrens, Journal Of Geophysical Research 114, B01203 (2009).

13. L. Stixrude, N. de Koker, N. Sun, M. Mookherjee and B. B. Karki, Earth And Planetary Science Letters 278, 226 (2009).

14. K. G. Holland and T. J. Ahrens, Science 275, 1623 (1997). 